\title{
Marie Unna hereditary hypotrichosis
}

INSERM

\section{Source}

INSERM. (1999). Orphanet: an online rare disease and orphan drug data base. Marie Unna hereditary hypotrichosis. ORPHA:444

Marie Unna hereditary hypotrichosis (MUHH) is a rare autosomal dominant hair loss disorder characterized by the absence or scarcity of scalp hair, eyebrows, and eyelashes at birth; coarse and wiry hair during childhood; and progressive hair loss beginning around puberty. 